\title{
STRATEGIES FOR THE ADOPTION OF OPEN TEXTBOOKS: THE LATIN AMERICAN OPEN TEXTBOOKS INITIATIVE
}

\author{
Virginia Rodés [virginia.rodes@cse.edu.uy],ManuelPodetti [mpodetti@cse.edu.uy], \\ Universidad de la República, Programa de Entornos Virtuales de Aprendizaje, José Enrique Rodó 1854, \\ Montevideo, Uruguay, \\ Yosly Hernández.[yosly.hernandez@ciens.ucv.ve], Universidad Central de Venezuela, Facultad de Ciencias, Av. \\ Los Ilustres, Los Chaguaramos, Caracas. ZP 1040, \\ CesarCollazos[ccollazo@unicauca.edu.co],Universidad del Cauca,Departamento de Sistemas,FIET-Sector \\ Tulcan, Popayán-Colombia
}

\begin{abstract}
Open textbook initiatives have emerged as an alternative to traditional publications, boosting the creation of educational resources based on open licenses. In order to make them sustainable, it is necessary to define strategies for the adoption of these initiatives by the different actors involved in the education institutions where they will be implemented. In this article we present the components of the adoption strategy designed for the LATIn Initiative. In Section 2 we present the relevant background information collected in a state-of-the-art reviewing. We then present in Section 3 the components defined for the Strategy for the Adoption of the LATIn Project. In this respect, in Section 4 we present the main processes defined. Furthermore, in Section 5 we identify the intervention of Actors and Contexts. Finally, in Section 6 we include the Phases of Implementation of the strategy, defined as Initial Phase, Generalization Phase and Institutionalization Phase. In Section 7 we present the Conclusions of this work.
\end{abstract}

Keywords: Adoption strategies, collaborative writing, open textbooks, Latin America

\section{Introduction}

Among the most important barriers for accessing and succeeding in the Latin American Higher Education Institutions (HEI) are the costs of being a university student. Even if there is not tuition to be paid, as in the case of most public HEIs in the region, or through scholarship from the government in private HEIs, other often overlooked costs, most notably the cost of textbooks, are real impediments for low-income prospective and actual students.

This problem has been traditionally addressed through the existence of university libraries that lend copies of the textbooks for free to the students. However, university libraries do not have the budget to meet the demand from low-income student as the costs for acquiring the material is too high for the purchasing power of most families.

One of the roots of the high cost of the textbooks is that most of them are produced outside the region. This root problem is not related with the lack of production capacity, but with the difficulty that local professors/authors have to publish and distribute their books. The problem with the origin of the textbooks have several additional consequences beside their cost: most textbooks are not tailored to the context of Latin American Higher Education, the most current versions are not available in a language in which most professors and students are fluent and it 
creates the harmful perception among students that knowledge always comes from outside the region.

Open textbook initiatives have emerged as an alternative to traditional publications, boosting the creation of educational resources based on open licenses. In that sense, the LATIn Initiative proposed an initiative for creation and adoption of open textbooks produced collaboratively by professors and other authors of the region. This initiative will encourage and support local professors and authors to contribute with individual sections or chapters that could be assembled into customized books by the whole community. The created books will be freely available to the students in an electronic format or could be legally printed at low cost because there is no license or fees to be paid for their distribution. This solution will also contribute to the creation of customized textbooks where each professor could select the sections appropriate for their courses or could freely adapt existing sections to their needs. Also, the local professors will be the sink and source of the knowledge, contextualized to the Latin American Higher Education system.

Professors and academic authors will be the main users of the proposed solution, however the low-income students will be the main beneficiaries of the freely available textbooks produced by the initiative. During pilot implementation of the initiative that is one of the proposed actions of this project, it is expected that the solution will help 144 courses in 9 different universities, with at total benefited population of more than 4,500 students in 6 months. The created textbooks will remain freely available to reuse, translate, adapt and remix.

In order to make the initiative sustainable, it is necessary to define the strategies for the adoption by the different actors involved in the education institutions where they will be implemented. In this article we present the components of the adoption strategy designed for theLATIn Initiative, which includes nine Latin American and three European universities.

In Section 2 we present the methods involved to relieve relevant background information to open textbook initiatives in different contexts. The information was collected in a state-of-the-art reviewing we did in order to identify the various models of strategies for the adoption of this kind of initiatives. We then present in Section 3 the main components defined for the Strategy for the Adoption of the LATIn Initiative. In this respect, in Section 4 we present the main processes defined: Dissemination, Promotion and Training. Furthermore, in Section 5 we identify the intervention of Actors and Contexts. Finally, in Section 6 we include the Phases of Implementation of the strategy, defined as Initial Phase, Generalization Phase and Institutionalization Phase. In Section 7 we present the Conclusions of this work.

\section{Methods}

In a previous state-of-the-art review (Rodés et al., 2012), we have mentioned some various strategies boost the adoption of Open Textbook initiatives. In that work we described some of the study cases associated to open textbooks initiatives, developed in different contexts and with different degrees of implementation and evolution (Giraldo, 2008; Vilaythong \& Calvo, 2009; Calvo et al., 2011; Bouamrane et al., 2004; Benjamin et al., 2002; Kanter et al., 2008; Anderson, 2008; Petrides et al., 2011; Lin et al., 2009). The analysis was aimed at identifying the components of the levels of implementation and adoption of these initiatives in various areas of intervention. For such purpose, we designed a systematized reading guide which focuses on extracting the most relevant aspects related to the implementation and adoption phases corresponding to the cases studied.

Regarding implementation, some of the aspects we tried to recognize were: how the initiative started and its motivations; who were the leaders and managers involved; which were the costs 
involved in the initiative and its funding; the recipients of the initiative; which was the scope of the initiative; the processes involved and the steps taken in these processes.

Also regarding implementation, some of the aspects we have tried to identify were: the communication strategy applied at different stages (beginning, generalization, and institutionalization); the external promotion and dissemination of the initiative; types of media used and stakeholders; which were the policies applied to encourage the participation of authors, teachers and students and the kind of licensing used.

As a remarkable consequence from the review, it is worth mentioning the identification and abstraction of three kinds of dimensions: time-related dimensions (processes/phases), social dimensions (actors/contexts) and communication dimensions (promotion/ dissemination). Details about them are provided in the next section.

\section{Results: Strategy for the Adoption of the LATIn Initiative}

The dissemination process of technological innovations is as relevant as the creation process of any technological system. This dissemination process of innovations, as per Rogers (2003), has four main elements:

1. an innovation,

2. that is communicated through certain channels,

3. in a given period of time,

4. among members of a given social system.

The Adoption strategy is defined as a systematic and well-planned series of actions that combine various methods, techniques and tools so as to be able to adopt the initiative, using the resources available and within a given time frame.

The planning and definition of an integral strategy to achieve and foster the adoption of an initiative that promotes innovation involves defining a set of actions to be taken, as specific plans, aimed at incorporating enthusiasts in the initial phase, and at reaching laggards in the shortest time possible.

In the review mentioned above we identified the dimensions that form a framework for a strategy for the adoption of an initiative of open textbooks in higher education context. We propose the strategy to be implemented in three phases, so as to involve different actors and contexts.

Three main processes were defined: Dissemination, Promotion and Training. Furthermore, we identified the intervention of Actors and Contexts; and also we recognized the Phases of Implementation of the strategy, defined as Initial Phase, Generalization Phase and Institutionalization Phase.

\section{Processes}

The Adoption Strategy to be implemented in a period of two years for this initiative is formed by three basic processes for the execution and acceptance of the collaborative creation of open textbooks. These are shown in Figure 1. 


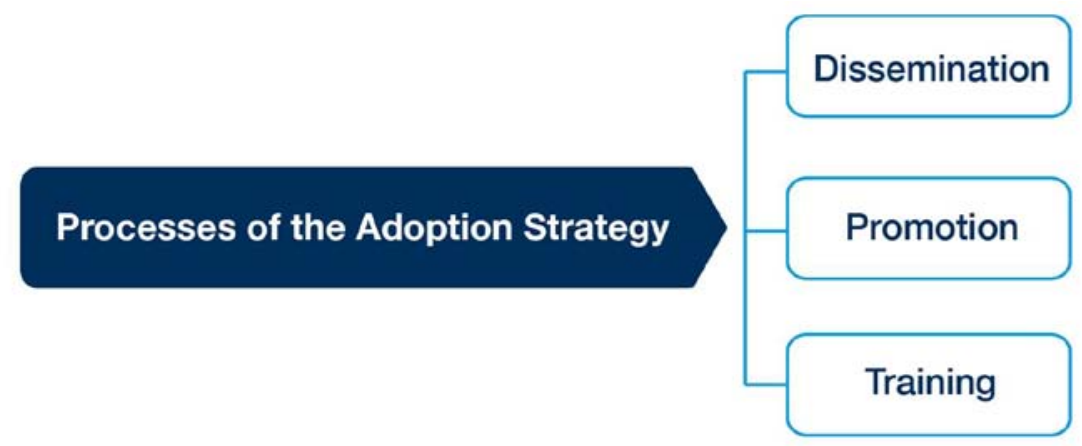

Figure 1. Processes of the Adoption Strategy

\section{Dissemination}

It involves dissemination and awareness-raising of the initiative on a broad level, through traditional means of communication (radio, TV), non-traditional means (internet, social networks) as well as face-to-face means (talks, conferences), together with key stakeholders in the participating institutions, in order to motivate and involve all actors in the creation, use, promotion and adoption of open textbook initiatives, as well as the benefits and opportunities they provide. It must be noted that the dissemination of innovative and/or technological matters requires different means and modalities so as to promote the adoption of the initiative, as there might be a number of people that are not related to the specific field.

With this aim in mind, we propose the following actions to ensure that the message of the initiative could be communicated successfully:

- Presentation of the initiative as well as a Contest for the collaborative and interinstitutional creation of open textbooks.

- Setting up and dissemination of the Contest on social networks, the press, internet and other means of interaction and communication of each of the Institutions part of the initiative.

- Presentation of the results of the Contest and of the winners from each university.

- Initial support for training in the basic and fundamental contents of the initiative.

- Content marketing of the driving ideas of the initiative and their impact.

- Advocacy and political influence.

- Internal communication among all actors and participating institutions.

The main products to be obtained as a result of this process are:

- Identity of the initiative, where the slogan, logo, website and other marketing materials are coherent with the aim of the initiative and make it possible to communicate this aim adequately and effectively.

- Virtual and/or face-to-face events, where the Initiative is presented and promoted (conferences, seminars, meetings, workshops, rounds, etc.) in every participating institution.

- Materials to present the initiative (videos, posters, bulletins, leaflets), as well as material announcing the Competition (official announcement, terms).

- Management by the participating Community, articles in the press, promotion in different institutional channels (institutional web, institutional TV, radio, etc.).

- Official announcement of the winners of the Competition.

- News and registration form to participate in the initiative. 
- White papers (designed as open books in the platform) connected with the philosophy of the project, Open Educational Resources (OER), Open Textbooks (OT), Creative Commons license (CC).

- Meetings with representatives of institutional sectors and presentation so as to promote the use of the books developed.

- Profiles on the platform, fostering the interaction between authors and communities.

- Launch of a publishing house that operates jointly with institutional publishing houses.

- Press releases, networks, website of the Initiative and of the participating institutions.

\section{Promotion}

This refers to the actions performed by institutions and the main actors to promote and foster the adoption, authoring and publishing of open textbooks, and the supplementary measures taken to facilitate the process. This is connected with the actions aimed at promoting participation in the initiative and focuses on the operational aspects of the creation, use and reuse of the contents.

We present the following actions to promote and foster the adoption of the initiative:

- Visibility and recognition of theLATIn brand.

- Clarification of legal issues, explaining how the authoring and copyright acknowledgement process works.

- Identification of institutional leaders in each participating University.

- Inspiration and motivation for all the participants from the institutions through the campaigns that disseminate the initiative.

- Finding the potential authors, creators and innovators, for the creation and use of open textbooks.

- Reaching the authorities and ensuring support for the creation and use of open textbooks.

- Promotion of the use and modification of open textbooks.

- Promotion of the creation and use of pen textbooks in the participating universities.

- Opening of the print and demand model jointly with the each university press.

- Agreements with OER, CC, as well as free culture and open knowledge.

- Liaison with similar initiatives and interconnection with actions and programs relative to the subject.

- Agreements of cooperation and use of the Open Publishing Platform by other educational institutions (primary, basic and secondary education, etc.).

- Collaboration with content aggregators (phone companies, repositories, online shops, digital bookshops).

- Events for the promotion of the Open Publishing House to disseminate experiences and good practices in the creation of open textbooks.

- Sustainability of the initiative over time. 
The main products to be obtained as a result of this process are:

- Meetings with university authorities and key institutional actors.

- Virtual and/or face-to-face Events such as: conferences, seminars, meetings, workshops, rounds, among others, jointly with all the participating institutions, as well as presentation materials (videos, posters, bulletins, etc.).

- Events, meetings, creation of Open Publishing House.

- Promotion of the publication of articles with reports of good practices.

- Creation of new projects and financing strategies.

\section{Training}

This refers to the actions taken for the institutions to train the actors, thus favouring the adoption of the necessary educational strategies to deal with the creation, use and reuse of open and collaborative textbooks.

Training includes the following actions:

- Call to faculties interested in the design and coordination or training workshops and courses.

- Education with open contents, which is one of the objectives of this project and also part of the pilot programme.

- Design and online publication of open course on community management and leadership for the institutional promotion of OER and OT.

- Design and online publication of open course on the driving ideas of the initiative such as OER, OT, open licenses, etc.

- Design and online publication of open course on how to create an OT in the Open Publishing platform, which can be supplemented with a course on how to create a book collaboratively.

- Tutorials that will serve as guides to better understand how each process of the initiative works.

- Licenses, which must be free so that access to knowledge is disseminated and used freely.

- Open access: the Initiative has been conceived so that anyone with an internet connection can have access to the information on the online system. Additionally, it will be possible to analyze the impact on students.

- Creation, educational material such as books, booklets, etc., the result of work that is collaborative and dedicated to the participants.

- Openbadges for the recognition of the skills

The main products to be obtained as a result of this process are:

- A group of course creators on open textbooks matters, with a format similar to that of Massive Open Online Courses.

- At least the managing team doing the open course on Community Management and Leadership for the institutional promotion of OER and OT matters.

- Managing team and community doing the open course on the driving ideas of the project: OER, OT and open licenses such as CC.

- Teachers who are authors doing the open course on how to create OT collaboratively on the Open Publishing platform promoted in the initiative. 


\section{Actors and contexts}

Within the adoption strategy, we identified the social sphere where the participation of different actors and their contexts is promoted. They are related to the people previously identified as institutional actors in charge of fulfilling different roles which are relevant to this initiative of collaborative creation of open textbooks. The actors identified can be internal and external.

Internal actors are those who operate within each of the Latin American university institutions that participate in the initiative. Internal actors include Teachers (academic staff directly involved in teaching), University Authorities (decision-makers and government authorities), Students, University Presses, University Libraries and Copy Centres in the various participating universities. These actors participate in various Institutional Contexts which may involve different degrees of action at macro level within the University, and at successive micro levels such as the School, the Faculty, the Subject and the Course.

External actors are those who work externally to a university institution, but who somehow have a strong influence on the university sphere. External actors include: Educational Leaders, Commercial Publishing Houses, National, Regional and International Academic Networks, Political Managers and Distributors.

The context where these actors exert their influence is varied in nature. Regarding the Institutional Context (internal), we can identify, at a macro level, the University, the School, and at a micro level the Faculty, Area, Department, Subject, or Course. Other contexts identified are the Geographical and Cultural contexts, which correspond to the areas connected with the territorial dimension, where we have different levels: International, Regional, National and Local. Figure 2 shows the relationship between actors and contexts.

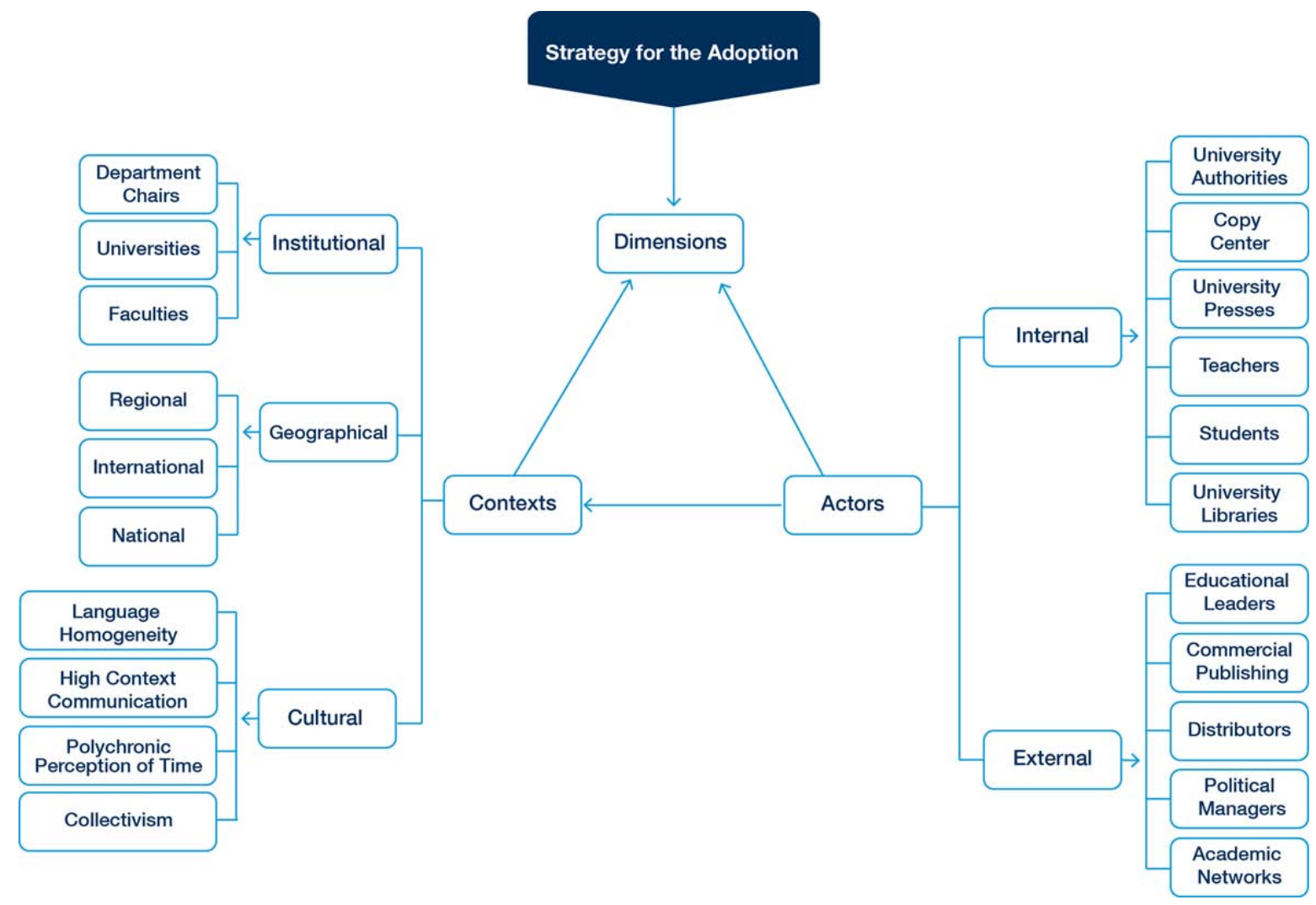

Figure 2. Relationship between the physical dimension contexts and the social dimension (based on Rodés et al., 2013) 


\section{Phases}

We defined a temporal dimension for this adoption strategy, in which three phases will take place during the two years: Initial Phase, Generalization Phase and Institutionalization Phase. This was done in order to promote the adoption of the initiative in each of the participating institutions, so that the initiative becomes an inter-institutional matter. This temporal dimension guides the action in the dimensions mentioned above which constitute the model of the initiative (see Figure 3). Below we describe the phases anticipated.

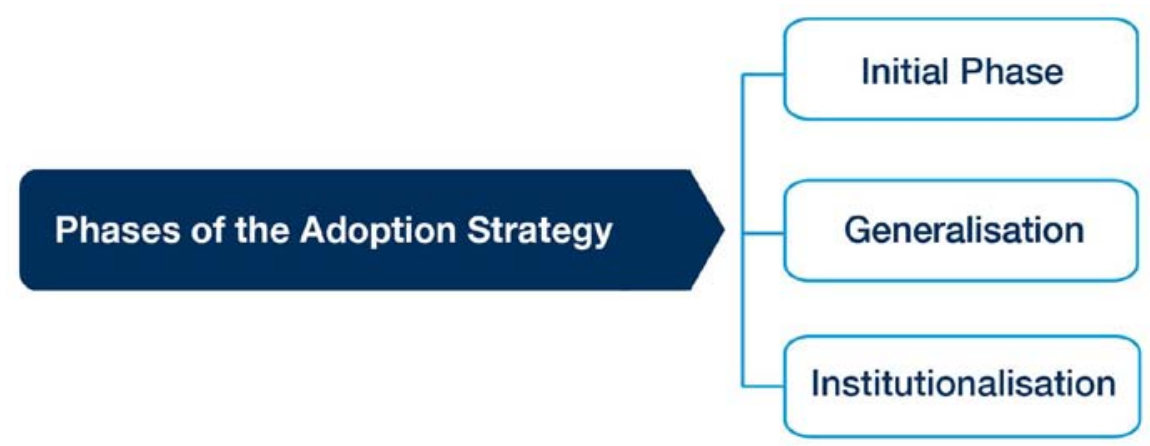

Figure 3. Phases of the Adoption Strategy

\section{Initial Phase}

There is a platform that was developed so that the teachers who wish to create books can indicate their areas of interest and the topic on which they want to write the book. The people who are registered will be able to find peers with interests in common and similar topics, and thus will be able to work in a group and participate in the competition to develop a book. A pilot programme is implemented so that users can have a first contact with the system.

The main aspects to consider are:

- Collaboration among students, where they take on an important role to reach this objective, mainly regarding two aspects: first because they provide their support and cooperation for the strategy launch; and second because they spread their interest among their peers so that it is possible to strengthen student support for tasks that require dedicated work;

- Collaborative text, seeking to enrich the content of the writings by the group assigned to this task in a participatory manner;

- Selected teachers work on the materials that have been written;

- A topic is selected and authors are invited. The objective of the platform is to allow the people who want to create books to indicate their areas of interest and the topic on which they want to write the book. The people who are registered will be able to find others with interests in common and similar topics, and thus will be able to work in a group and participate in the competition to develop a book;

- A recognized teacher is selected to guide participants in the process of creating a book. 


\section{Generalization Phase}

In this phase, the defined actions are determined, actions directed to every actor involved and focused on how they are connected with the initiative. Teachers and students create, use, reject and evaluate, constantly throughout the development process of the initiative.

The main aspects to consider are:

- Committee of peer reviewers, formed by two people, which will be responsible for checking the quality of the desired final product;

- Teachers and students create, use, evaluate the open textbooks constantly throughout the development process of the initiative;

- Pilot programme that must operate correctly so that users have a first contact with the system, through what is known as the Competition;

- Training of the participating actors.

\section{Institutionalization Phase}

This phase will take place after generalization, when institutions and authorities understand the benefits of the initiative and can adopt of it. The main aspects to consider in this process are:

- Integration with institutional library systems and university presses. This will make it possible to work in a joint and coordinated manner, facilitating timely access to information;

- Institutionalized roles and functions, necessary to understand and guide the relationship among those involved in this process in the best possible way;

- Sustainability, as the initiative has been conceived to remain operational and functional for several years over time;

- Creation of programmes for authoring, use and reuse of open textbooks, as well as licensing policies that respect the legislation of each participating country.

\section{Conclusions and further work}

In this article we have presented a framework for the adoption strategy defined within the LATIn Project. An adoption model is as important as the process of creation of collaborative textbooks itself. Without a plan where each and every participant in the process feels involved, it will be very difficult to have a successful process. This is why in this proposal we discuss processes, actors, contexts and phases that should be considered in any process of adoption of initiatives of this kind.

It is expected that, at the end of the LATIn Project the model will have been validated. It is also expected that a framework of reference will be available so that it can be the basis for adoption strategies to be applied, not only for theLATIn initiative, but also for initiatives connected with Open Education in Latin America. 


\section{References}

1. Anderson, C. (2008). Free! Why $\$ 0.00$ is the future of business. Retrieved from: http://www.webcitation.org/5gMD8PNy2

2. Benjamin, P.; Conan, A.; Lee, J. and Nunamaker, J. Jr. (2002). Users experiences in collaborative writing using Collaboratus, an Internet- based collaborative work. In Proceedings of the 35th Hawaii International Conference on System Sciences.

3. Bouamrane, D.; King,L. and Masoodian, M. (2004). Framework for collaborative writing with recording and post-meeting retrieval capabilities. In Proceedings of the Sixth International Workshop on Collaborative Editing Systems, Chicago, November 6, 2004. IEEE Distributed Systems Online Journal on Collaborative Computing.

4. Calvo, R.; Stephen, O.; Jones, J.; Yacef, K. and Reimann. (2011). Collaborative Writing Support Tools on the Cloud. In IEEE Transactions on Learning Technologies.

5. Giraldo, M. (2008). Metodología para la Construcción Colaborativa Hipertextos: El caso de Hipernexus en Educación Superior. In Revista Q - Revista electrónica de divulgación académica y cientifica de las investigaciones sobre la relación entre Educación, Comunicación y Tecnología, 3(5), (p. 22). ISSN: 1909-2814.

6. Kanter, M.; Baker, J.; Foothill-De Anza, J. (2008). Sustainability Models for Community College Open Textbooks. Community College District. Sanford Forte, Community College Open Text Project.

7. Lin, M.; Sajjapanroj, S. and Bonk, C. (2009). Wikibooks and Wikibookians: Loosely-Coupled Community or the Future of the Textbook Industry. In proceedings of W orld Conference on Educational Multimedia, Hypermedia and Telecommunications, Vol. 2009, (pp. 3689-3697). Retrieved Sept 9, 2012 from http://editlib.org/p/32013

8. Petrides, L.; Jimes, C.; Middleton-Detzner, C.; Walling, J. and Weiss, S. (2011). Open textbook adoption and use: implications for teachers and learners. In Open Learning The Journal of Open Distance and eLearning, 26(1), (pp. 39-49).

9. Rodés, V.; Solano, C.; Maturana, J.; Hernández, Y.; Cuadros, E.; Podetti, M. (2012). Strategies for Implementing the Adoption of Open Textbooks Initiatives: State of the Art Review. 1st Journal Conference on e-Education, e-Business, e-Management and e-Learning (2013 JC4E 1st), Rome, Italy.

10. Rodés, V.; Hernández-Bieliukas, Y.; Podetti, M; Collazos, C.A. (2013). Estrategia de Adopción para la Iniciativa LATIn Producción Colaborativa de Libros de Textos Abiertos. In LACLO 2013 - Octava Conferencia Latinoamericana de Objetos y Tecnologías de Aprendizaje, Valdivia, 2013, Vol 4, No 1. ISSN/ISBN: 19821611. http://www.laclo.org/papers/index.php/laclo/article/view/149

11. Rogers, E.M. (2003). Diffusion of innovations (5th edition). New York, NY: Free Press.

12. Vilaythong, K. and Calvo, R. (2009). WriteProc: A Framework for Exploring Collaborative Writing Processes. In Proceedings of the 14th Australasian Document Computing Symposium, Sydney, Australia.

\section{Acknowledgement}

The authors of this paper recognize the sponsorship of the European Union through the LATIn Project (DCI-ALA/19.09.01/11/21526/279-155/ALFA III(2011)-52) Funded by the ALFA Program, an initiative of EuropeAid. 